\title{
ESTRATEGAS, DE GEDEÓN A JACK WELCH
}

\section{STRATEGIST, FROM GEDEON TO JACK WELCH}

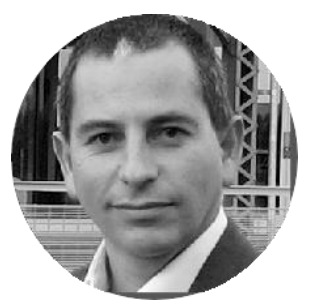

\section{Danilo Macera}

Código ORCID: 0000-0003-4915-8530 Profesor

Escuela de posgrado de la Universidad San

Ignacio de Loyola (USIL). Lima, Perú

Correspondencia: danilomacera@gmail.com

Recibido: 13 de agosto de 2019

Aprobado: 25 de setiembre de 2019

Cómo citar este artículo:

Macera, D. (2019). Estrategas: de Gedeón a Jack

Welch. Review of Global Management, 5(2), 20-27.

\section{RESUMEN}

En este ensayo se presenta un paralelo entre algunos ejemplos de estrategas militares a lo largo de la historia y una selección de casos del ámbito empresarial contemporáneo. Se plantean algunos elementos, comunes entre los estrategas empresariales y los militares, que determinaron el éxito o el fracaso en sus empresas. Se aborda el origen de la estrategia en antecedentes militares y se destaca su papel determinante, tanto en la guerra como en la gestión empresarial.

Palabras clave: Estrategia, estrategia empresarial, estrategia militar, origen de la estrategia, liderazgo. 


\section{ABSTRACT}

This essay raises a parallel between some examples of military strategists throughout history and a selection of cases from the contemporary business world. Some elements, common to both business and military strategists, are identified and discussed, that determined the success or failure of their business firms. The origin of the strategy is found in military history, and, as it addressed, its determining role is highlighted in war, as in business management.

Keywords: Strategy, business strategy, military strategy, origin of the strategy, leadership.

Mucho se habla de cómo la estrategia, nacida en los campos de batalla, ha desembocado inevitablemente en el mundo de los negocios. No se nos hace extraño escuchar a un directivo citar a un Sun Tzu o a Clasewitz, para explicar, por ejemplo, por qué no es conveniente entrar a un nuevo mercado, o por qué, debemos lanzar un nuevo producto de bajo precio. ¿Es la gestión estratégica empresarial, un eco de las acciones de los grandes generales de la historia? 0 ¿es un problema freudiano no resuelto, de aspiración personal de nuestros directivos, que necesitan probar su valor en batalla?

Laffin (2004) refiere la batalla bíblica que al grito de "la espada de Dios y de Gedeón", su comandante guía a 300 israelitas a media noche en contra de los madianitas que invadían sus tierras, armados ellos con una trompeta, un jarro y una tea. La estrategia de Gedeón era muy sencilla, consistió en provocar el pánico en las filas enemigas; y, sin duda, así fue, el sonar de las trompetas y la luz de las teas en la oscuridad de la noche debe haber sido una imagen apocalíptica para los medianitas, quienes entre el temor y la sorpresa fueron fácilmente derrotados. Tres mil años después, muy adelantados en el siglo XX, en 1984 para ser precisos, un músico folk y artista callejero llamado Guy Laliberté, enfrentó a fuerzas aún más grandes que los medianitas, las del espectáculo circense tradicional, con sus leones, elefantes, estrellas de renombre y múltiples pistas. 
La estrategia fue la de un espectáculo sin leones ni elefantes, estrellas de renombre, ni tampoco con múltiples pistas, pero sí con un tema o hilo conductor, un ambiente refinado, múltiples producciones, música y danza artística; es así como nació el Cirque du Soleil (Circo del Sol). Kim y Mauborgne (2005), citan este caso de éxito en su libro Blue Ocean Strategy1 resaltando la importancia de la innovación como el medio fundamental para el éxito empresarial, esto, sin contradecir absolutamente a Clausewitz (2002), quien declara que la estrategia está, sobre todo, al servicio del objetivo de la guerra, es decir, de la victoria.

Lee (2003), refiere lo ocurrido en la primavera del año 312, cuando se libró la batalla del Puente Milvio, entre los ejércitos de los emperadores Constantino I y Majencio. Como sabemos, esta batalla, talvez, sea la causante de que el cristianismo hoy sea la religión predominante en el mundo. Los historiadores cristianos, visiblemente influidos por la narración de Eusebio de Cesarea, imputaron el triunfo de Constantino a una intervención divina. Según se refiere, Constantino vio en el cielo un símbolo divino acompañado

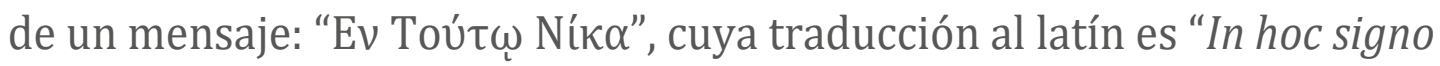
vinces" y al castellano "En este signo, vencerás". Cuenta la historia que a continuación, Constantino ordena a su ejército delinear un símbolo en sus escudos, la cruz latina o "estaurograma" o "crismón" que es como se nombran las representaciones del cristograma, es decir, el monograma de Cristo, y que consiste en la superposición de las letras griegas $\mathrm{X}$ (chi) y $\mathrm{P}$

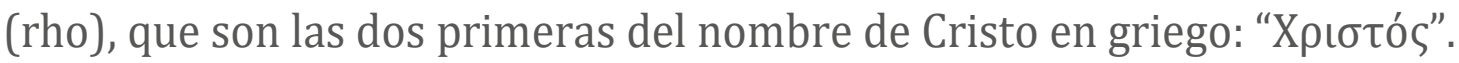

Poco más de 17 siglos más tarde, Forbes, en 2016, declaraba a Nike, una de las marcas más valiosas del mundo (Trullols, 2016). En el ranking mundial, Nike registró la posición número 18, con un valor de casi \$ 28 mil millones, coronándose, ciertamente, como la más valiosa entre las marcas deportivas, algo que refleja en gran medida la dirección de Mark Parker, su CEO. Y es precisamente la marca, una de las estrategias de diferenciación más sólidas que las empresas utilizan para lograr un férreo posicionamiento y la lealtad de sus clientes.

Glodman y Papson (2007), celebran el enorme valor de la marca Nike (pese a sus detractores) y su famoso símbolo "Swoosh", el que busca transmitir el movimiento en su diseño y simboliza el ala de Nike, la diosa griega de la victoria, ¿Coincidencia? 
Laffin (2010) rememora la mítica batalla de Maratón, en el año 491 a.C. Milcíades al frente de un ejército muy inferior en número, se pone al frente en superioridad psicológica sobre su enemigo, iniciando el ataque en dirección a la fuerza más formidable del mundo antiguo: el ejército persa, algo, que ningún ejército había hecho hasta entonces. Para Darío, era impensable que la insignificante Atenas pudiera hacerle frente a la poderosa Persia. Sin embargo, para cuando los griegos dieron fin a la batalla, una vez obligaron a retroceder a los persas, esta registraba alrededor de 6,400 muertos, entre las huestes persas y apenas 192 entre las huestes griegas. Esta batalla, es, tal vez, la evidencia más desproporcionada de una victoria y que, nos recuerda el enfrentamiento bíblico de David (que luego sería Rey de Israel), armado con una honda y cinco piedras, ante el gigante Goliat, el filisteo de casi tres metros (seis codos y un palmo).

Una de las marcas más reconocidas y poderosas, que desde su inicio lideró el desarrollo comercial de la fotografía, fue, sin duda, Kodak. Collins y Porras (2004), refieren cómo esta marca gozó por 130 años de una posición de liderazgo en el mercado. Ello, gracias a innovaciones tecnológicas sin precedentes, mediante la que pudo llegar a ejercer una posición de dominio cuasi-monopólica. No solo registró cuotas de mercado de $70 \%$ y más. También estuvo entre las 20 empresas más lucrativas del mundo en los años '90, según Forbes (Ochoa, 2015). Para dimensionar el desastre "maratónico", que le sobrevino en el siglo XXI, basta con mencionar que, en 2004, sus acciones cotizaban a $\$ 30$ y ocho años después, se desplomaron hasta los 27 centavos, para días más tarde acogerse al capítulo 11 de la ley de quiebras estadounidense. Una ironía, es que Kodak 1996 ya contaba con un modelo de cámara fotográfica digital. Sin embargo, la dirección de Antonio Pérez, su CE0 desde 2005, cuestionaba que la fotografía digital pudiese reemplazar a la fotografía tradicional, comercialmente. Metafóricamente, Pérez era un relojero suizo mirando con desdén su nueva invención, "el reloj de cuarzo". Kodak subestimó a sus competidores, empresas como Nikon, Cannon o Sony que entonces se limitaban al mercado de la fotografía que Kodak dejaba de lado. Estas empresas envistieron sin piedad a la poderosa Kodak, haciéndose de su mercado. Kodak, al igual que Darío, sobrestimó el poder de su marca, pensando que podrían sumarse a la carrera digital en cualquier momento, basándose en la ventaja sobre sus competidores, de ser Kodak. 
Greene (2012) refiere la ferocidad de Eduardo de Inglaterra, un rey guerrero del siglo XIII, cuyo estilo despiadado y deseo expansionista hizo que en un corto tiempo conquiste todas las islas británicas. Tras vencer a los galeses, dirigió la vista hacia Escocia; arrasó y sometió a cada pueblo que invadió, siendo aún más cruel con aquellos que oponían resistencia, entre ellos el célebre héroe escoceses, William Wallace, a quien le dio caza, torturó y descuartizó públicamente. Aun los lores escoceses se sometieron a su tiranía, salvo el conde de Carrick Robert Bruce, quien en 1306 se hizo coronar rey de Escocia y juró expulsar a los ingleses de tierras escocesas. Eduardo, estaba resuelto a terminar con el infame y conservar el imperio que había creado, pero en el año 1307 tras su muerte es sucedido por su hijo Eduardo II,quien no tenía ni el interés por expandir el imperio, ni las habilidades mi- litares de su padre.

A los pocos meses del ascenso al trono de Eduardo II,Bruce tomó algunos castillos escoceses y los quemó, para luego hacer lo propio con los campos de cultivo, limitando los recursos de los ingleses. Por fin, en 1314, decidió enfrentarlos y vencerlos en la batalla de Bannockburn. En 1322, Eduardo II llevó a cabo una nueva campaña contra Robert Bruce, pero éste, arrasó con los recursos, ya no solo en tierras escocesas, sino también en el norte de Inglaterra. El hambre y las enfermedades diezmaron al ejército Inglés. El desastre de esta campaña trajo consigo una rebelión que terminó con la captura y asesinato de Eduardo II. En 1323, el nuevo rey, Eduardo III, hijo del fenecido o Eduardo II, renunció a las aspiraciones de Eduardo I y negoció la paz con Escocia, reconociendo su independencia y a Robert Bruce como su Rey.

Casi 750 años antes en Japón, (año 578), el príncipe japonés Shotoku contrató a la familia Kongo para la construcción del templo budista Shiten- noji, así, inicia operaciones la constructora Kongo Gumi. A lo largo de los siguientes 14 siglos, la empresa desarrolló innumerables proyectos como el castillo de Osaka (siglo XVI). Lipman (2010), presenta a su último CEO Masakazu Kongo, quien asegura que la larga vida de la compañía reside, principalmente, en las decisiones de sucesión altamente flexibles a la hora de elegir a sus líderes. La empresa no se aferró a la tradición japonesa de ascender al hijo mayor, la sucesión recayó siempre en el más capaz para el puesto, independientemente del género. Tras 1,428 años de operaciones, la empresa dejó de operar, en parte, por cambios culturales y en parte por la 
falta de recursos críticos, en este caso no era la falta de alimentos o las enfermedades, si no, la falta de disponibilidad de efectivo. Aunque, si sufrió una grave enfermedad: el endeudamiento, excesivo que la llevó, a quebrar en el año 2006.

En las palabras de Greene (2012), Napoleón fue el mejor director de hombres de la historia. Él fue capaz de atender diversos asuntos simultáneamente y de dirigir a sus soldados en la dirección correcta de la victoria, haciendo uso de pocas horas de sueño. Napoleón era famoso por sus políticas respecto a los ascensos, orientadas a promocionar a sus soldados por mérito. Esto hacía que percibieran que, si se esforzaban, podían llegar a mariscales. Laffin (2010), resalta la personalidad magnética de Napoleón, que le permitía, infundir fuego a sus palabras. Napoleón, formó un ejército que se podía desplazar a una velocidad muy superior a la de los ejércitos de la época. Desarrolló la idea de que las divisiones que actuaban en forma independiente debían converger en un objetivo común. Conocía a muchos de sus soldados por su nombre, y asignaba tareas a sus generales cediéndoles autonomía total, tanto en la concepción de la estrategia, como en su ejecución. Napoleón, se preocupó por que sus soldados compartieran los beneficios de la victoria. Conocía las ideas de sus antecesores: Saxe, Guilbert, Pierre de Bourcet, Anibal, Julio Cesar, Alejandro, Escipión, Milciades, Arminio, Eduardo III, Condé, Gustavo, Turenne, Vend ôme, Eugenio y Marlborough, por mencionar algunos. El corso, consideraba innecesario defender o tomar una posición que no fuera claramente alcanzable.

Heller (2001), sitúa a Jack Welch como el gerente corporativo más importante de finales de siglo XX. Lo describe con una increíble energía, capaz de entusiasmar a otros, y de definir una visión para ganar sus mentes y corazones. Cuando Welch, se convirtió en CEO de General Electric, desplegó la llamada "guerra relámpago", gracias a la cual, a una velocidad inusitada, los negocios de gigantesca firma se convertían en primeros o segundos de sus industrias, o eran reestructurados o vendidos. Welch, conocía a sus empleados por su nombre y sus facultades para cubrir nuevas posiciones; creía en la importancia de la delegación; y de fomentar las nuevas ideas. Welch, se preocupó en reconocer el valor de sus empleados. Así, subió los salarios y beneficios muy por encima del mercado; y ascendió y premió 
el esfuerzo y desempeño. Buscaba, aplicar las mejores prácticas del mercado, de las que implementó el pensamiento de calidad de Deming y Six Sigma. Welch, solía decir que jugaba para ganar; y, como sabemos, hizo algo más que eso: en 1981, cuando asumió la dirección de GE, la compañía estaba valorizada en casi \$ 14 mil millones y, para el otoño de 1999, dicho valor había aumentado casi 30 veces, a casi $\$ 41$ mil millones.

Si Gedeón, contribuyó a la concepción del Cique du Soleil, y, Constantino I, influyó de algún modo en la creación del Swoosh de Nike, aun, si es Antonio Pérez, una reencarnación moderna de Darío, si lo es Masakazu Kongo de Eduardo III, o es Jack Welch un heredero del genio de Napoleón, son interrogantes, que no podemos responder. No obstante, es indudable que Guy Laliberté es un inno- vador sobresaliente; que Mark Parker dirige una marca multimillonaria; que la labor de Antonio Pérez, como CEO de Kodak es una de las más cuestionadas en la historia reciente; que Kogo Gumi dejó de operar después de más de catorce siglos; y que Jack Welch, al término del siglo XX, fue considerado el CEO del milenio.

Sean ecos del pasado, o nostalgia instintiva, la estrategia es vital tanto en la guerra como en la gestión empresarial. Greene (2012), sugiere que sea la guerra o cualquier forma de confrontación, ésta se gana mediante la estrategia; y podríamos agregar que se pierde cuando se prescinde de ella. La gestión empresarial implica competencia, incluso, estando inmersos en océanos azules. Como sabemos, cuando dos o más competidores persiguen el mismo objetivo, existe una confrontación inevitable. La preparación de un ejército o de una empresa, el conocimiento de su entorno circundante y de sus enemigos o rivales, así como la pericia y dotes de liderazgo de sus generales o directivos, el contar con los recursos de todo orden, en la medida y oportunidad necesarias, entre otros factores, determinarán el desenlace de la batalla o de la competencia por el mercado. 


\section{REFERENCIAS}

Clausewitz, K. (2002), De la Guerra, Buenos Aires, Librodot.

Collins,J.\& Porras,J. (2004), Built to Last: Successful Habits of Visionary

Companies, London, William Collins.

Greene (2012), Las 33 estrategias de la guerra, Madrid:Espasa.

Goldman, R. \& Papson, S. (2007) La cultura NIKE, El signo del swoosh.

Barcelona: Deustuo.

Kim W. C., \& Mauborgne, R. (2005). Blue ocean strategy: How to create uncontested market space and make the competition irrelevant. Cambridge, MA: Harvard Business School Publishing Co.

Laffin, J., (2004) Grandes Batallas de la Historia, Buenos Aires, El Ateneo. Lee, L. (2003) The Battle 100: The Stories Behind History's Most Influential Battles. Naperville, Illinois: Source books, Inc.

Lipman (2010) The Family Business Guide: Everything You Need to Know to Manage Your Business from legal planning to business estrategies. New York, Pallgrave Macmillan

Ochoa, C. (2015). El caso Kodak, mucho que aprender. Recuperado de https://www.netquest.com/blog/es/blog/es/el-caso-kodak

Trullols, J. (2016). El informe publicado por Forbes muestra el crecimiento de Nike, que entra en el top 20 de las marcas más valiosas del mundo. Recuperado de http://lajugadafinanciera.com/valormarca-nike-2016/ 